\title{
Fotografía Documental en los ambientes histórico-religiosos de la Universidad Nacional Mayor de San Marcos
}

\author{
Oscar Pacheco Romero \\ Departamento Acadénico de Comunicación Social
}

L.

a Fotografia documental se nutre de imágenes de vestigios culturales, artísticos y científicos de épocas pasadas y como una máquina registradora enfila su ojo fotográfico en dirección del mundo antiguo, grabando esos escasos remanentes para su preservación infinita y salvaguarda el patrimonio cultural, difundiendo valores a una sociedad civilizada. Este mundo de vestigios históricos, en una época actual, parece estar amenazada por el infortunio, por el saqueo y el hurto por bandas especializadas.

La irremediable pérdida de los bienes y objetos artisticos se produjo también en épocas de cruenta guerra. Los bienes de la Universidad Mayor de San Marcos fueron afectados sin que algún defensor pudiera hacer algo. Por ejemplo, entre muchas otras riquezas sustraidas encontramos varias copas de oro, un valioso reioj de arena, una campana de plata grabada en el afio 1550 , obsequio a la Universidad por el rey de Espafía, Carlos $V$, que fueron retiradas de los claustros por la soldadesca chilena que en orgla sangrienta celebraba a su manera los triunfos de la guerra del Pacifico, en 1880.

Hoy tenemos réplicas que finamente reproducen las caracteristicas de los objetos perdidos, actualmente en el Rectorado. Las fotografias de las réplicas permiten, sin embargo, el conocimiento real de los obsequios y su posterior inclusión en la historia sanmarquina.

La Fotografia Documental también se nutre de la soledad de los campos entibiados por el cálido sol de la puna, orienta su mira a la faena comunitaria; se dirige a los terrenos de la industria moderna, apoya la industria de turismo, y avanza en la jlustración de las ciencias futuristas. En este sentido la actividad documental se desplaza con libertad hacia el pasado, en el presente y futuro. Pero al actuar en el pasado histórico rescata las imágenes, las eleva al terreno de la actualidad y las pone al servicio de las generaciones presentes. 
Las imágenes documentales enriquecen el saber, rescatan los valores y afianzan la identidad. Dan apoyo al plano educativo graficando obras de consulta, textos escolares y universitarios, diccionarios ilustrados y libros especializados. En la televisión es ampliamente conocida la labor del cine documental y su difusión de la arqueologia, biologia e historia, además del arte y de otras ciencias.

En el año 1994 fui encomendado por autoridades sanmarquinas para fotografiar los ambientes históricos y riquezas artístico-culturales de la universidad; así pude enterarme que en la pinacoteca las pinturas en reserva yacen en ambientes oscurecidos por el paso del tiempo. Los retratos al óleo de los primeros rectores y personajes relacionados con la vida académica sanmarquina, con la teología, las artes y la jurisprudencia, de los siglos XVI, XVII y XVIII, están depositados en una zona de almacenamiento donde apenas ingresa la luz del día como medida que salvaguarda la naturaleza policroma de las pinturas. Algunos retratos muestran sin embargo el oscurecimiento propio del paso de los siglos que esconde los rasgos fisonómicos y el color de las vestimentas del personaje bajo una capa negruzca, que a modo de barniz muy oscuro oculta la verdadera apariencia del personaje retratado. Producido el oscurecimiento resulta dificil pronosticar las facciones verdaderas del personaje salvo un tratamiento de retoque que puede partir de una fotografia tomada previamente en las décadas finales del siglo XIX, o en el XX. De no ser así y al no haber un registro de la verdadera apariencia se presentan momentos difíciles para el restaurador que podria terminar en una éspèceie deacrobacia mental paga replantear la verdadera fisonomia. Es también el efecto del smog urbano la contaminación ambiental, los gases liberados por el parque automotor en calles y avenidas de la gran Lima, sumándose negativamente los humos de fundiciones, fábricas e industrias instaladas en el perímetro urbano; es poco lo que se puede hacer para detener este proceso químico irreversible en los estratos superficiales y profundos de las capas de óleo. Las pinturas del Convenio de Santo Domingo, en el centro de Lima, y los tesoros bien conservados del Convento de Santa Catalina, de la ciudad de Arequipa muestran también los efectos del envejecimiento.

Es aquí donde surge como medida providencial la técnica de la restauración, del retoque y de la conservación, que convertidas en ciencias aliadas del arte creativo pictórico intervienen en justo tiempo para retomar el estilo del original para imprimirle un sello de autenticidad. Así, en estado remozado lucen muchas pinturas para el visitante de las galerías sanmarquinas donde aprecia el retrato en su fresco estado como acabado de pintar. 
El trabajo de copiado del cuadro por un experto, imitando estilo y gama cromática del original se emplea para preservar el cuadro original como se puede observar en museos de otros paises, donde también se acostumbra copiar cuadros para la venta.

La práctica fotográfica documental puede intervenir para duplicar en pelicula blanco y negro, y en colores, cuadros de personajes importantes, conservando la autenticidad del cuadro. $Y$ es sobre este punto donde se acentuará el tema del presente escrito.

La copia de un cuadro pictórico por medio de la cámara fotográfica convencional implica la ubicación de la cámara frente a frente al lienzo, guardando un paralelismo de la máquina con la superficie del cuadro. Lo que se tiene en mente es que el.trabajo conduce a la obtención de una toma fotográfica que pueda ser empleada para su difusión cultural porque existe riesgo de pérdida del cuadro bien sea por el paso del tiempo cubriéndose de la capa negruzca descrita, o por un voraginoso incendio, desastre natural, o por acto delincuencial. Por eso el copiado fotográfico conseryará el estilo, composición, color, para su publicación en textos de arte, enciclopedias, diccionarios, etc. Mientras tanto el cuadro original permanece en su pais de origen celosamente vigilado, y la toma fotográfica permite su difusión en los paises del mundo occidental. La misma labor cumple la cámara digital.

Para un copiado perfecto se requiere que el lente de la cámara apunte al centro geométrico del cuadro debiendo estar la cámara a la misma altura del centro. El lente gran angular no es empleado frente a cuadros individuales porque puede alterar la perspectiva del cuadro, descuadrando el marco propiamente dicho, prefiriéndose el lente normal en los espacios amplios cuidando de diagramar adecuadamente para lograr amplia profundidad de campo. Sin embargo en la foto inferior fue adecuado el uso del lente gran angular ( $F=24 \mathrm{~mm}$.) obteniendo nitidez en los cuadros y elementos arquitectónicos. Se trata de un toma de conjunto del Salón Capitular (Convento de Santo Domingo, Lima).

La toma de naturaleza descriptiva del recinto histórico justifica el empleo del granangular.

La importancia de las fotografias publicadas nos trae a la memoria que fue en el Salón Capitular donde en el año I $5 \$ 1$ fue fundada la Universidad Nacional Mayor de San Marcos; ahi se dictó la primera clase de Teologia, época en que la universidad tenía dos facultades, Teologia y Artes (hoy letras). 


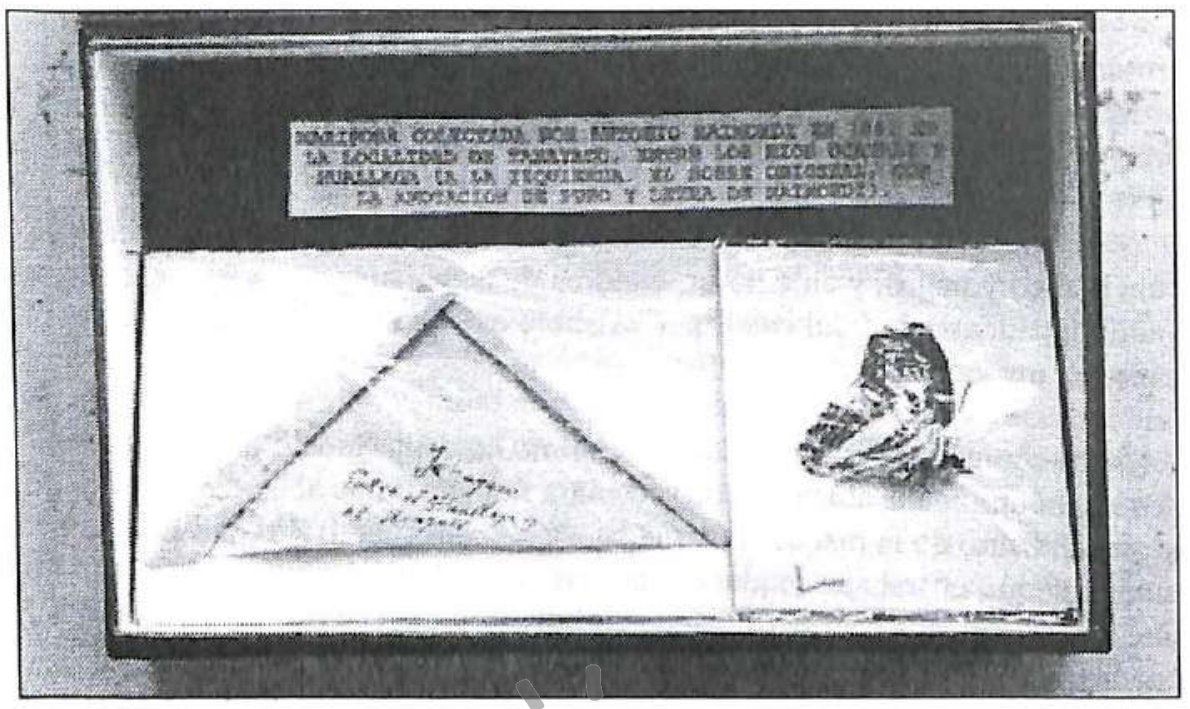

Foto 1: Salón Capitular. Convento de Santo Domingo, Lima. Ahi se fundó en 1551 la Universidad de San Marcos.

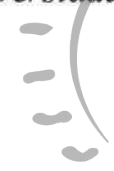

La foto I denotaamplia profundidad de campo por el uso del lente granangular y porque se empleó diafragma f/ 1 . Un lente más corto, por ejemplo de $\mathrm{F}=$ $20 \mathrm{~mm}$. hubiera abarćado mutuchó frás del recintoy la toma hubiera gozado de una mayor capacidad descriptiva.

En la parte superior del púlpito que se encuentra en el centro de la capilla apreciamos un pequeño retrato al óleo de Santo Tomás de Aquino (Patrono de las universidades de América, como nos explicó una guía de turismo en reciente visita al claustro). Se trata de un cuadro de $30 \times 40$ centimetros que solamente puede ser fotografiado desde unos 12 metros de distancia con un lente zoom teleobjetivo (zoom 70-300 mm.) para no crear distorsión en las medidas del cuadro.

La foto 2 fue captada con luz natural pero se tuvo que emplear exposición prolongada para la película $(\mathrm{V}=3$ segundos) por cuanto que en el claustro histórico el ingreso de luz es escaso. El diafragma f/8 aseguró nitidez en los contornos de la fotografía. 


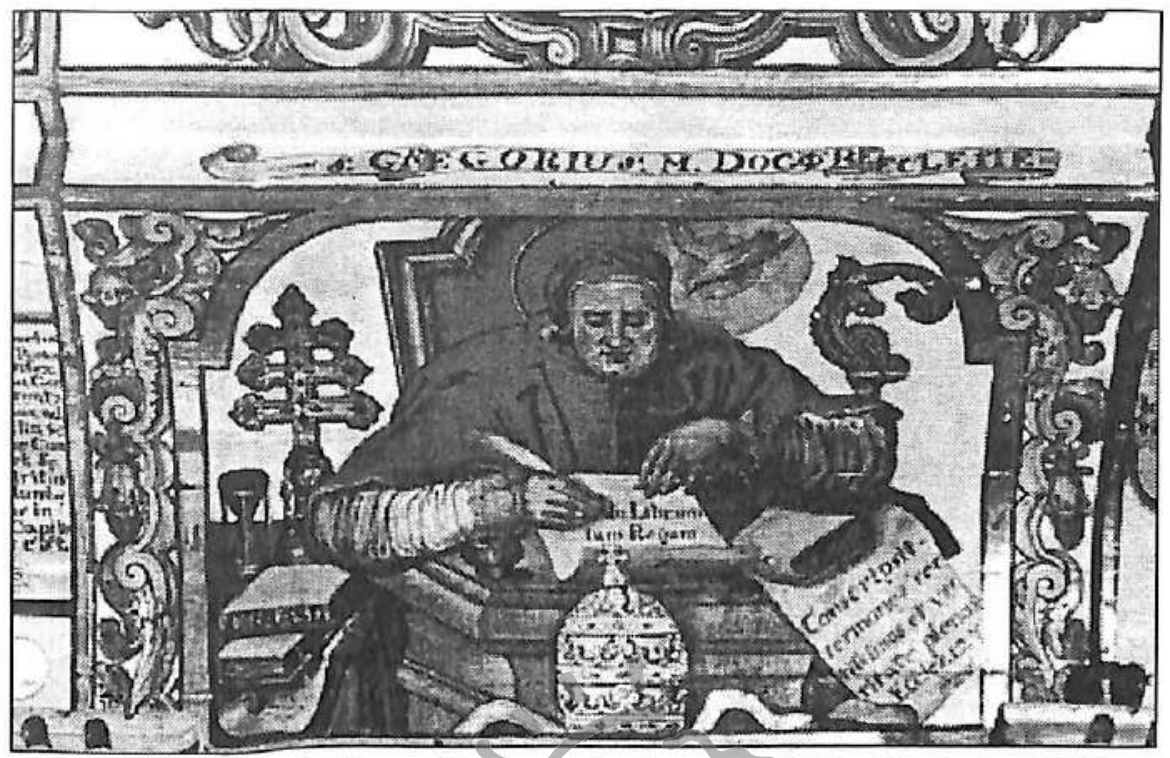

Foro 2: Retrato de Santo Tomás de Aquino en el Salón Capitular del Convento de Santo Domingo, Lima.

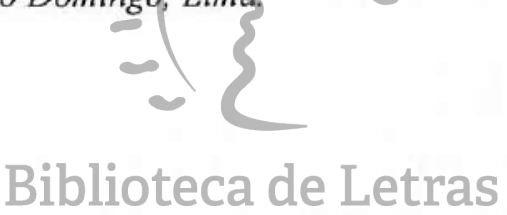

El mismo zoom teleobjetivo fue empleado para fotografiar la pintura mural en el techo o bóveda de la Capilla de la Virgen de Loreto, del ex-convictorio de San Carlos (Casona de San Marcos). Para que el nivel de nitidez no decayera se empleó un diafragma f/11 estando la cámara apoyada en el trípode. El lente largo es empleado por el documentalista cuando el cuadro se encuentra colgado a gran altura, cuando es imposible acercarnos, y también cuando deseamos reproducir un detalle significativo, el rostro de un personaje, por ejemplo.

En la foto 3, la toma con cámara convencional recogió el detalle del inmenso mural a través del zoom en posición 300 milímetros. Se empleó la escasa luz diurna de la Capilla por lo que también fué necesario una prolongada exposición de película de 4 ó 6 segundos.

El trabajo fotográfico documental en museos, pinacotecas, conventos, monasterios y galerías de arte se efectúa con película negativa en colores y 


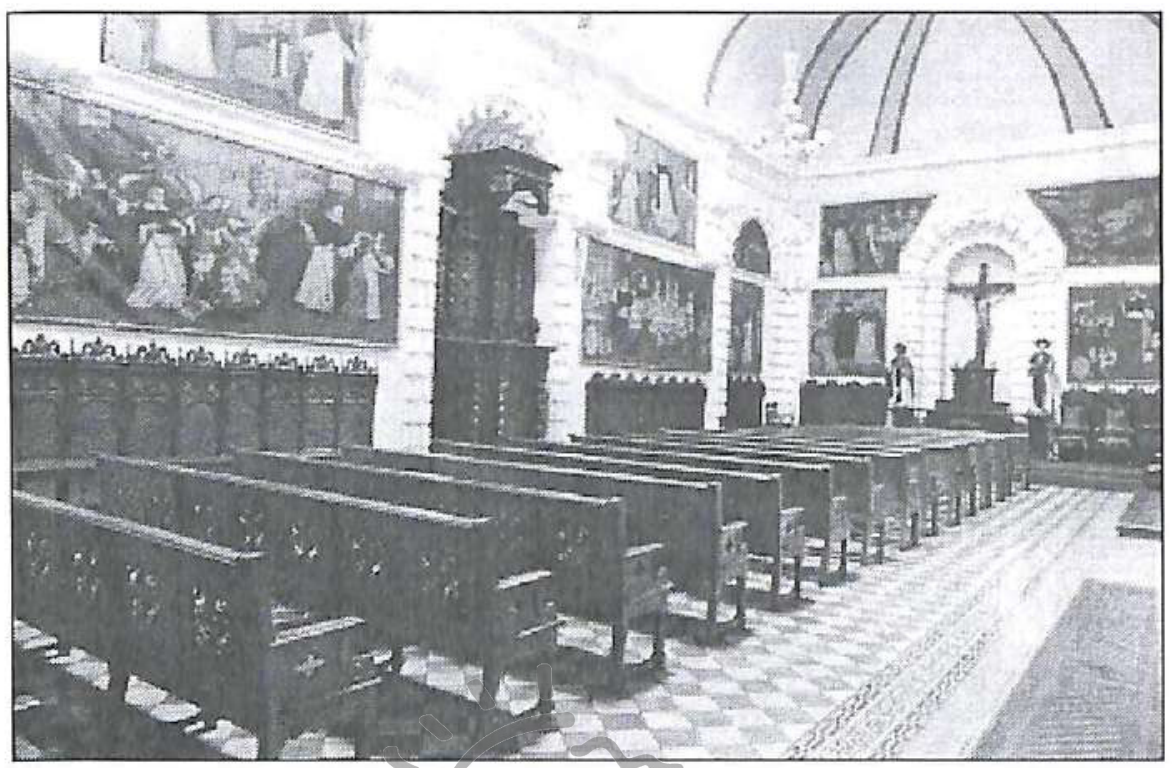

Fото 3: Detalle del mural existente en la bóveda de la Capilla de la Virgen de Loreto, ex-convictorio de San Carlos (Casona de San Marcos).

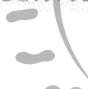

pelicula para transparencia en colores, de sensibilidad mediana, por ejemplo, 100 ISO y 400 ISO. Se da preferencia alla película-de slides cuando se trata de impresión en libros de arte, catálogos, enciclopedias, afiches, tripticos, etc., por ejemplo Kodak Elite Chrome 100 ISO para transparencias en colores. Si deseamos fotos en blanco y negro podemos emplear la pelicula Kodak Professional $\mathrm{T}$ $400 \mathrm{CN}$.

En conclusión, la labor documental se realiza a gran distancia (en el caso de las pinturas de la bóveda de la capilla de la Virgen de Loreto). La visión documental es también panorámica, como en el caso del Salón Capitular. También le interesa una visión muy cercana para resaltar pequeños detalles, no captados a simple vista. Nos referimos a la fotografía del manuscrito que no sólo evoca la idea estampada en letras sino también la caligrafía y el ritmo de la escritura.

En la foto 4 corresponde a un manuscrito del sabio Antonio Raimondi quien a su paso por la ceja de la selva peruana en 1,861 recolectó una mariposa, habiendo trazado con su propia letra una anotación en el sobre de papel 
Bond en cuyo interior se halló el insecto disecado. Para el efecto, acoplé a la cámara convencional un macrolente de $\mathrm{F}=55$ milimetros para realizar una macrofotografia cuya operación resultó exitosa produciendo nitidez en la superficie del sobre y en el manuscrito. El ejemplar citado pertenece a la colección entomológica del Museo de Historia Natural, de la Universidad Nacional Mayor de San Marcos, que gentilmente la mostró. En un clima de seguridad y cumpliendo con todas las condiciones de protección que el Museo exige en este caso único, pude efectuar el registro especifico que engalana a la Universidad de San Marcos por poseer las riquezas artísticas más destacadas en el ámbito latinoamericano.

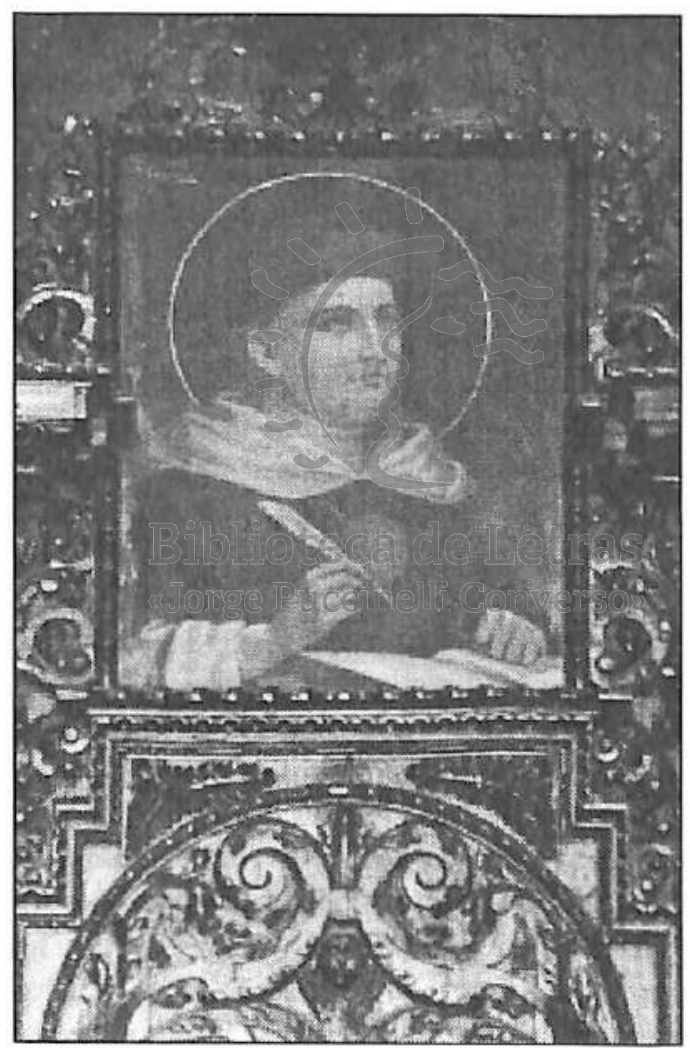

Fото 4: Macrofotografia de un sobre con escritura de puño y letra del sabio Antonio Raimondi, propiedad del Museo de Historia Natural de la Universidad Nacional Mayor de San Marcos. 